\title{
APLIKASI PENGENALAN FAKULTAS KOMUNIKASI DAN INFORMATIKA UNIVERSITAS MUHAMMADIYAH SURAKARTA MENGGUNAKAN VIRTUAL REALITY 360 DERAJAT
}

\author{
Abu Nizar Zulmi \\ Program Studi Informatika Universitas Muhammadiyah Surakarta (UMS) \\ Surakarta, Indonesia.Zarazu88@gmail.com \\ Umi Fadlilah \\ Program Studi Teknik Elektro Universitas Muhammadiyah Surakarta (UMS) \\ Surakarta, Indonesia. Umi.Fadlilah@ums.ac.id
}

Teknologi merupakan aspek yang sangat penting di era modernisasi ini, hampir disetiap lini kehidupan memerlukan bantuan teknologi untuk mempermudah pekerjaan. Melalui teknologi, hampir setiap informasi diseluruh dunia dapat diakses dengan mudah dan cepat. Informasi yang didapat tidak hanya sekedar berbentuk tulisan saja, namun dapat juga dalam bentuk lain seperti foto atau gambar. Salah satu jenis teknologi foto yaitu foto Virtual Reality (VR) 360 derajat, seseorang dapat merasakan seolah-olah ada di dunia nyata melalui teknologi ini. Penulis menggunakan teknologi ini untuk memperkenalkan Fakultas Komunikasi dan Informatika Universitas Muhammadiyah Surakarta (FKI UMS) kepada mahasiswa yang benar-benar belum mengetahui tempat-tempat yang ada di fakultas mereka sendiri. Penulis membuat aplikasi ini sebagai media interaktif dengan menambahkan suara narasi, mode VR, denah lantai, dan fitur lainnya. Aplikasi berbasis web ini dibuat dengan 2 aplikasi utama yaitu Kolor AutoPano Giga dan Kolor Panotour Giga serta aplikasi pendukung lainnya. Pembuatan aplikasi ini menggunakan metode Luther Sutopo, metode ini memiliki beberapa tahapan yaitu Konsep, Desain, Pengumpulan Data, Pembuatan, Pengujian, dan Distribusi. Berdasarkan hasil pengujian kepada mahasiswa/mahasiswi FKI UMS dapat disimpulkan bahwa rata-rata sebanyak 86,89\% responden menyatakan bahwa aplikasi ini dapat bermanfaat dan membantu mengenal lebih dalam tentang FKI UMS.

\section{Kata Kunci: FKI UMS, Foto 360 Derajat, Virtual Reality}

\section{PENDAHULUAN}

Dari tahun ke tahun Fakultas Komunikasi dan Informatika Universitas Muhammadiyah Surakarta (FKI UMS) adalah salah satu fakultas yang selalu bertambah peminatnya. Banyaknya mahasiswa dan calon mahasiswa FKI UMS kurang pengetahuan tentang informasi fakultasnya sendiri. Mahasiswa yang bukan dari daerah surakarta pasti mencari informasi baik dari web, brosur maupun lainnya. Informasi yang diberikan masih kurang dan membuat para mahasiswa belum mengetahui tempat-tempat mana saja yang akan mereka gunakan.

Dari permasalahan di atas, solusi yang ditawarkan adalah gambaran nyata dari setiap ruangan FKI UMS secara digital yang disajikan melalui Aplikasi Virtual Reality (VR) 360 Derajat. Aplikasi ini dibuat agar memudahkan para mahasiswa, calon mahasiswa, serta masyarakat umum dalam mengenal ruangan yang akan digunakan walaupun terkendala oleh jarak dan waktu.

Pelaksanaan Tugas Akhir (TA) yang serupa dilakukan Fachri R. Daud (2016) dengan judul Virtual Tour Panorama 360 Derajat kampus Universitas Sam Ratulangi Manado. Penelitian tersebut mengambil spot foto panorama setiap fakultas dan sekitarnya. Aplikasi ini dilengkapi Peta plan, Bing Map, Music dan dipublikasikan ke Google Maps dan Google Street View. Beberapa kekurangan yang dijadikan sebuah saran yaitu diharapkan 
aplikasi tersebut agar lebih interaktif dan user interface diperbaiki lagi. [1]

Kemudian pelaksanaan TA yang serupa juga dilakukan Aditya Fatkur Pudyanto (2014) dengan judul Pemodelan Virtual Reality One Day Service sebagai Media Informasi Pendaftaran Mahasiswa Baru Universitas Muhammadiyah Surakarta. Penelitian tersebut menggunakan model animasi 3D sebagai media informasi, dilengkapi dengan suara dan teks informasi. Penulis membuat TA ini dikarenakan para calon mahasiswa UMS kurang mengerti alur pendaftaran, kurangnya staff admisi ODS dan antrian yang panjang. Untuk hasil responden rata-rata memberikan penilaian yang positif. [2]

Pelaksanaan TA yang penulis kembangkan ini dengan memanfaatkan fitur-fitur tambahan seperti denah setiap lantai, mode VR, info teks disetiap tempat, autorotation, suara dubbing (narasi) dan lain-lain. Sehingga dengan dibuatnya aplikasi VR 360 derajat ini dapat lebih menarik dan digunakan dengan mudah. Aplikasi ini bertujuan untuk mempermudah mengenalkan beberapa tempat yang ada di FKI UMS tanpa harus datang langsung ke lokasi.

\section{DASAR TEORI DAN TINJAUAN PUSTAKA}

VR merupakan sebuah teknologi yang membuat seseorang seolah-olah berada disuatu tempat yang nyata didalam dunia maya dengan menggunakan komputer. Teknologi ini dapat berinteraksi langsung dengan objek 3D sehingga membuat user seolah-olah terlibat secara fisik. Selain dengan objek 3D, salah satu jenis lainnya yaitu panorama 360 derajat yang menggunakan foto dengan sudut 360 derajat. Contohnya seperti Google Street View di Google Maps yang menggunakan teknologi ini. [3]

VR 360 Derajat adalah sebuah teknik yang dapat melihat sebuah foto panorama sudut lebar secara interaktif. Sebuah foto VR 360 derajat ini menampilkan suasana yang nyata dari lingkungannya. Pandangan 360 derajat ini seolah-olah kita berada di pusat bola dan melihat sekeliling kita secara spherical. [4]

Panorama memiliki cakupan yang luas, termasuk VR, video 2D/3D interaktif, telekonferensi, kompresi video berbasis manipulasi, dan video full-view. Lensa dengan pandangan yang luas seperti fish-eye atau lensa panorama dapat menjadi solusi untuk mendapatkan panorama. Cara membuat panorama 360 derajat dengan meniru urutan gambar yang ditangkap melalui kamera biasa atau kamera beresolusi tinggi. [5]

\section{METODE}

Pada pelaksanaan TA ini ada 2 bagian yaitu Analisis Kebutuhan dan Metode yang digunakan.

\section{A. Analisis Kebutuhan}

Menganalisis kebutuhan yang diperlukan dalam pembuatan aplikasi VR 360 Derajat.

\section{Alat dan Bahan}

Alat dan bahan yang akan digunakan untuk membuat aplikasi VR ini dipaparkan pada Tabel 1 dan 2 .

Tabel 1. Hardware

\begin{tabular}{cl}
\hline No. & \multicolumn{1}{c}{ Hardware } \\
\hline 1. & Laptop MSI GL62 6QE Intel ${ }^{\circledR}$ Core $^{\mathrm{TM}}$ \\
i7-6700HQ CPU @ 2.60GHz, RAM 8GB, \\
Harddisk 1TB \\
2. Kamera Nikon D5200 Lensa Sigma Fish \\
Eye 8mm f/3.5 \\
3. BUB Microphone untuk Smartphone \\
\hline
\end{tabular}

Tabel 2. Software

\begin{tabular}{l} 
No. Software \\
\hline 1. Kolor Panotour Pro 2.5 \\
Aplikasi tur virtual profesional yang \\
menyajikan dunia 360 derajat secara nyata \\
dengan panorama dan transisi. Suara, \\
Teks, Gambar Denah, Video, Maps, dan \\
beberapa fitur lain yang dapat dijelajahi \\
dalam tur virtual. \\
2. Kolor Autopano Giga 4.4 \\
Software jahitan atau penggabungan \\
beberapa foto untuk menghasilkan gambar \\
panorama. Sepengetahuan saya software \\
ini yang paling mudah digunakan dengan \\
User Interface yang sederhana dan ringan \\
tetapi hasil maksimal. Tidak hanya UI saja, \\
tetapi dalam editing foto panorama dapat \\
kita manipulasi atau menghilangkan \\
bagian yang tidak dibutuhkan.
\end{tabular}


3. Format Factory 3.9.5

Software konverter multifungsi yang dapat mengubah semua jenis file audio, video, maupun gambar.

4. Adobe Premiere Pro CC 2015

Aplikasi editing video dan dubbing suara. Selain itu untuk mempermudah memotong suara menjadi beberapa bagian.

5. Adobe Photoshop CS6

Aplikasi untuk memanipulasi foto sesuai kebutuhan agar hasilnya maksimal.

\section{B.Metode yang digunakan}

Sistem pelaksanaan TA ini menggunakan metode Luther Sutopo, ada 6 tahapan yaitu Tahap Konsep, Tahap Desain, Tahap Pengumpulan Data, Tahap Assembly, Tahap Pengujian, dan Tahap Distribusi. Alur dijelaskan dalam bentuk Gambar 1 .

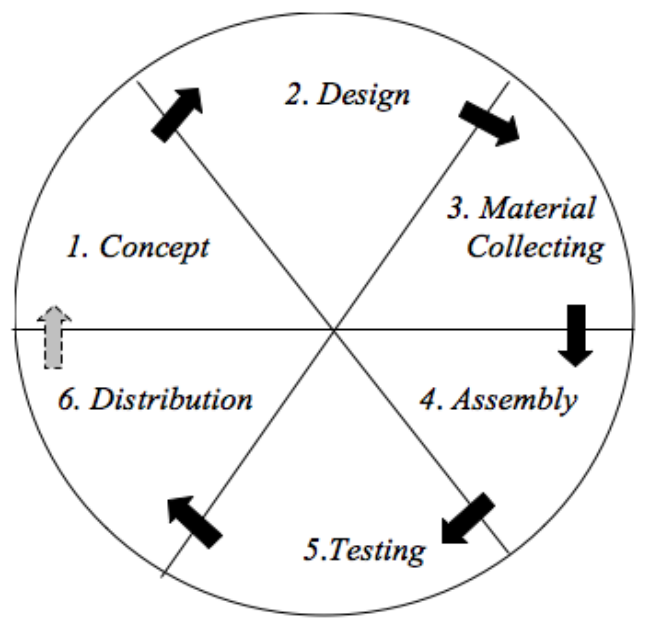

Gambar 1. Metode Luther Sutopo

\section{Konsep}

Konsep aplikasi ini dapat dideskripsikan dalam bentuk Tabel 3.

Tabel 3. Konsep Aplikasi

\begin{tabular}{clr}
\hline No.Spesifikasi & \multicolumn{2}{c}{ Keterangan } \\
\hline 1. Judul & Aplikasi Pengenalan & Fakultas \\
& Komunikasi dan Informatika Universitas \\
& $\begin{array}{l}\text { Muhammadiyah } \\
\text { Surakarta }\end{array}$ \\
& $\begin{array}{l}\text { Menggunakan Virtual Reality } 360 \\
\text { 2. Fungsi }\end{array}$ & Untuk memudahkan para mahasiswa, \\
& calon mahasiswa, serta masyarakat \\
& umum dalam mengenal dan mendapat
\end{tabular}

informasi setiap ruangan secara visual.

3. Jenis Aplikasi Media Interaktif

4. Pengguna Mahasiswa, Calon Mahasiswa FKI UMS, dan Masyarakat Umum.

5. Input Foto, Teks, dan Audio (backsound dan audio narasi)

6. Output Foto 360 Derajat, Teks, dan Audio (backsound dan audio narasi)

\section{Desain}

Pada aplikasi VR 360 Derajat ini, user dapat melihat halaman awal, melihat tampilan 360 derajat, melihat denah lokasi, memutar/mematikan background musik/suara dubbing, memutar ke kiri, kanan, atas, bawah, menampilkan thumbnail, menggunakan VR Mode, menampilkan informasi teks, mengaktifkan/mematikan autorotation dan mengatur zoom in dan zoom out. Use Case ditampilkan dalam bentuk Gambar 2 .
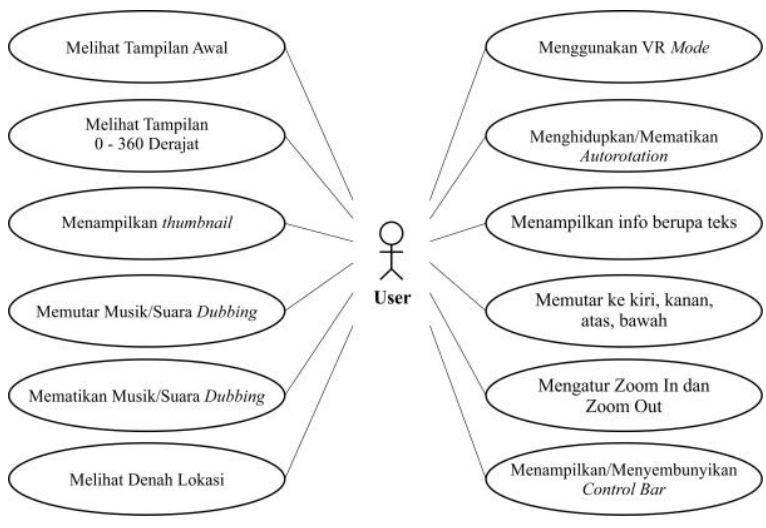

Gambar 2. Use Case Aplikasi

Adapun User Interface dari aplikasi VR 360 derajat ini yang dijelaskan pada Tabel 4 .

Tabel 4. User Interface Aplikasi

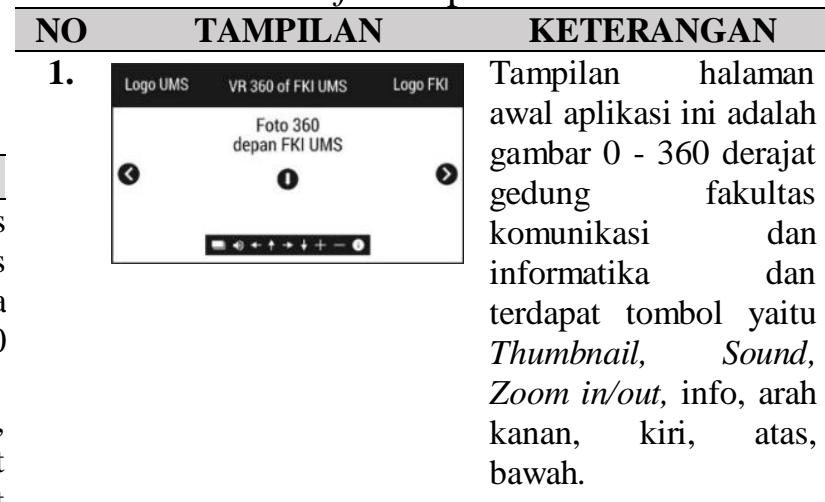


2.

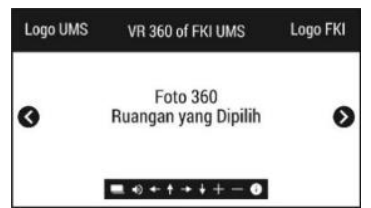

3.

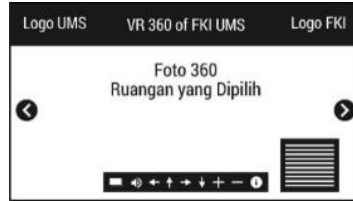

4.

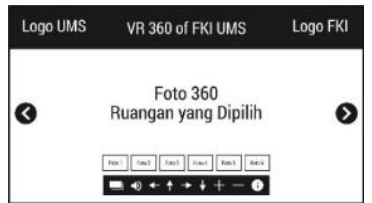

\section{Pengumpulan Data}

Foto 360 Derajat

Data yang diperlukan untuk membuat aplikasi VR 360 derajat ini mengumpulkan beberapa foto setiap ruangan atau tempat. Setiap ruangan harus mencakup foto dari atas, kanan, kiri, dan bawah tetapi untuk jumlah foto setiap ruangan berbeda-beda dan akan dipaparkan pada Tabel 5.

Tabel 5. Pengumpulan Data

\begin{tabular}{|c|c|c|c|c|}
\hline \multirow{3}{*}{$\begin{array}{c}\text { NO } \\
\cdot\end{array}$} & \multicolumn{2}{|c|}{ Lantai 1} & \multicolumn{2}{|c|}{ Lantai 2} \\
\hline & Nama & Jumlah & Nama & Jumla \\
\hline & Ruangan & Foto & Ruangan & Foto \\
\hline 1. & Depan & 6 & Lantai 2 & 6 \\
\hline & Gedung FKI & & Tengah & \\
\hline 2. & Hall Gedung & 6 & R. Dosen & 10 \\
\hline & FKI & & Komunikasi & \\
\hline 3. & $\begin{array}{l}\text { Depan JSEM } \\
1\end{array}$ & 6 & $\begin{array}{l}\text { Sayap Kiri } \\
\text { Lt. } 2\end{array}$ & 6 \\
\hline 4. & JSEM 1 & 6 & $\begin{array}{l}\text { Depan R. } \\
\text { J205 }\end{array}$ & 7 \\
\hline 5. & $\begin{array}{l}\text { Depan JSEM } \\
2\end{array}$ & 9 & Ruang J205 & 6 \\
\hline 6. & JSEM 2 & 8 & $\begin{array}{l}\text { Depan R. } \\
\text { Dosen } \\
\text { Informatika }\end{array}$ & 6 \\
\hline 7. & $\begin{array}{l}\text { Ruang } \\
\text { Tengah } \\
\text { Kantor }\end{array}$ & 10 & $\begin{array}{l}\text { R. Dosen } \\
\text { Informatika }\end{array}$ & 10 \\
\hline 8. & $\begin{array}{l}\text { Ruang Wakil } \\
\text { Dekan }\end{array}$ & 6 & $\begin{array}{l}\text { Sayap Kanan } \\
\text { Lt. } 2\end{array}$ & 6 \\
\hline 9. & $\begin{array}{l}\text { Pojok Tangga } \\
\text { Lt. } 1\end{array}$ & 6 & $\begin{array}{l}\text { Depan Lab. } \\
\text { Komunikasi }\end{array}$ & 6 \\
\hline 10. & $\begin{array}{l}\text { Tangga Lt. } 1 \\
\text { ke } 2\end{array}$ & 9 & $\begin{array}{l}\text { Lab. } \\
\text { Komunikasi }\end{array}$ & 11 \\
\hline 11. & & & Studio TV & 10 \\
\hline
\end{tabular}

12.

Tangga Lt. $2 \quad 6$

ke 3

\begin{tabular}{|c|c|c|c|c|}
\hline \multirow{2}{*}{ NO } & \multicolumn{2}{|c|}{ Lantai 3} & \multicolumn{2}{|c|}{ Lantai 4} \\
\hline & $\begin{array}{l}\text { Nama } \\
\text { Ruangan }\end{array}$ & $\begin{array}{l}\text { Jumlah } \\
\text { Foto }\end{array}$ & $\begin{array}{l}\text { Nama } \\
\text { Ruangan }\end{array}$ & $\begin{array}{l}\text { Jumlah } \\
\text { Foto }\end{array}$ \\
\hline 1. & $\begin{array}{l}\text { Lantai } 3 \\
\text { Tengah }\end{array}$ & 6 & $\begin{array}{l}\text { Lantai } 4 \\
\text { Tengah }\end{array}$ & 6 \\
\hline 2. & Lab. RPL & 15 & $\begin{array}{l}\text { Sayap Kiri } \\
\text { Lt. } 4\end{array}$ & 6 \\
\hline 3. & $\begin{array}{l}\text { Sayap Kiri } \\
\text { Lt. } 3\end{array}$ & 6 & $\begin{array}{l}\text { Depan R. } \\
\text { J405 }\end{array}$ & 6 \\
\hline 4. & $\begin{array}{l}\text { Depan Lab. } \\
\text { Informatika }\end{array}$ & 6 & Ruang J405 & 6 \\
\hline 5. & $\begin{array}{l}\text { Lab. } \\
\text { Komputer } \\
\text { FKI }\end{array}$ & 8 & $\begin{array}{l}\text { Depan R. } \\
\text { J404 }\end{array}$ & 7 \\
\hline 6. & $\begin{array}{l}\text { Lab. Sistem } \\
\text { Informasi }\end{array}$ & 8 & Ruang J404 & 6 \\
\hline 7. & $\begin{array}{l}\text { Sayap Kanan } \\
\text { Lt. } 3\end{array}$ & 6 & $\begin{array}{l}\text { Depan R. } \\
\text { J403 }\end{array}$ & 6 \\
\hline 8. & $\begin{array}{l}\text { Depan R. } \\
\text { Multimedia }\end{array}$ & 6 & Ruang J403 & 6 \\
\hline 9. & $\begin{array}{l}\text { Ruang } \\
\text { Multimedia }\end{array}$ & 12 & $\begin{array}{l}\text { Sayap Kanan } \\
\text { Lt. } 4\end{array}$ & 6 \\
\hline 10. & $\begin{array}{l}\text { Lab. Jaringan } \\
\text { Komputer }\end{array}$ & 9 & $\begin{array}{l}\text { R. } \\
\text { Internasional } \\
1\end{array}$ & 7 \\
\hline 11. & $\begin{array}{l}\text { Tangga Lt. } 3 \\
\text { ke } 4\end{array}$ & 6 & $\begin{array}{l}\text { Depan R. } \\
\text { J407 }\end{array}$ & 7 \\
\hline 12. & & & Ruang J407 & 8 \\
\hline 13. & & & $\begin{array}{l}\text { Depan R. } \\
\text { J408 }\end{array}$ & 6 \\
\hline 14. & & & Ruang J408 & 6 \\
\hline 15. & & & $\begin{array}{l}\text { Depan R. } \\
\text { J409 }\end{array}$ & 6 \\
\hline 16. & & & Ruang J409 & 6 \\
\hline 17. & & & $\begin{array}{l}\text { Depan R. } \\
\text { J410 }\end{array}$ & 6 \\
\hline 18. & & & Ruang J410 & 6 \\
\hline
\end{tabular}

\section{Kuisioner}

Kuisioner ini dilakukan dengan membagikan beberapa pertanyaan kepada mahasiswa FKI UMS untuk mengetahui lokasi ruangan yang ada di FKI UMS. Pengumpulan kuisioner dilakukan dengan cara mengisi form secara online melalui Google Forms.

\section{HASIL DAN PEMBAHASAN}

6 Pada bagian ini ada 3 tahap melanjutkan pembahasan sebelumnya yaitu Assembly (Pembuatan Aplikasi), Testing (Pengujian), dan Distribution (Hasil Akhir). 


\section{A. Assembly}

Sebelum aplikasi ini dibuat, penulis sebelumnya menentukan tempat/ruangan mana saja yang akan dikumpulkan. Kemudian proses pengambilan foto di Gedung FKI UMS ada 4 lantai yang berjumlah 51 titik yang mana 1 titiknya berjumlah 6-15 foto tergantung luas tempat/ruangannya. Untuk pengambilan foto ini penulis lakukan 3 kali, pengambilan pertama hanya 22 titik yang berhasil digabung. Kemudian pengambilan kedua mendapat 46 titik, dan pengambilan terakhir hanya mengambil kekurangan sebelumnya yang berjumlah 51 titik.

Setelah mengumpulkan semua foto, penulis menggabungkan beberapa foto setiap titiknya dengan menggunakan software yaitu Kolor AutoPano Giga. Untuk proses penggabungan hampir $80 \%$ membutuhkan aplikasi tambahan yaitu Adobe Photoshop CS6, karena saat pengambilan foto, penulis tidak menggunakan alat khusus (manual). Jadi, foto 360 derajat (foto yang sudah digabungkan), masih ada beberapa bagian yang kurang pas. Teknik yang digunakan software ini yaitu mencari bagian yang sama dari beberapa foto tersebut dan jika kurang pas dapat menggunakan teknik masking (dapat dilihat pada Gambar 3).

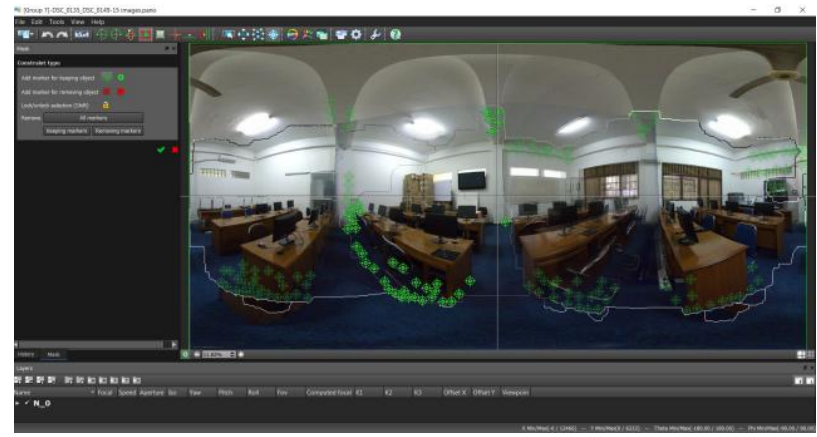

Gambar 3. Proses Penggabungan Foto menjadi 360 derajat di Kolor AutoPano Giga

Kemudian penulis membuat dubbing suara per tempat yang diperlukan, totalnya berjumlah 34 suara. Setelah dikumpulkan, lalu di olah menggunakan software Adobe Premiere Pro agar suara lebih jernih (dapat dilihat pada Gambar 4).

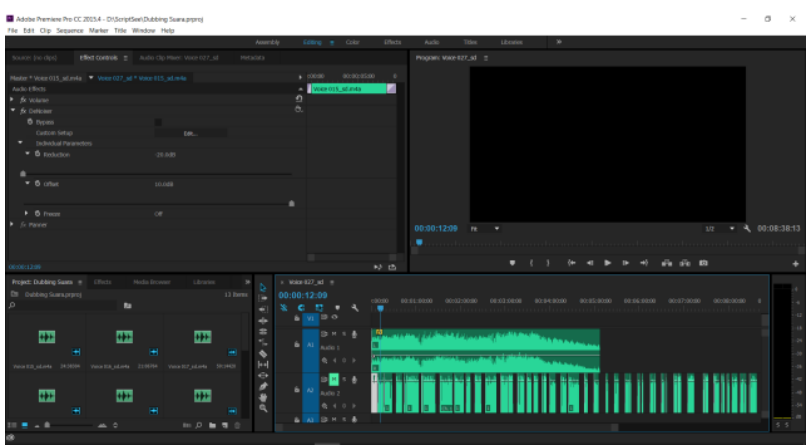

Gambar 4. Pengolahan dubbing dan backsound di Adobe Premiere Pro

Lalu hasil semua foto 360 derajat tersebut dilanjutkan ke tahap pembuatan (assembly) aplikasi VR 360 derajat dengan menggunakan software Kolor Panotour Giga. Penulis mengimport foto yang sudah digabungkan tadi kemudian disambungkan dan ditata sesuai lantai. Setelah itu membuat user interface sehingga aplikasi itu dapat ditambahkan spot untuk berpindah tempat, menambahkan dubbing suara, backsound musik, denah floor plan, informasi tambahan berupa teks, navigasi yang mudah dioperasikan, dan lain-lain (dapat dilihat pada Gambar 5).

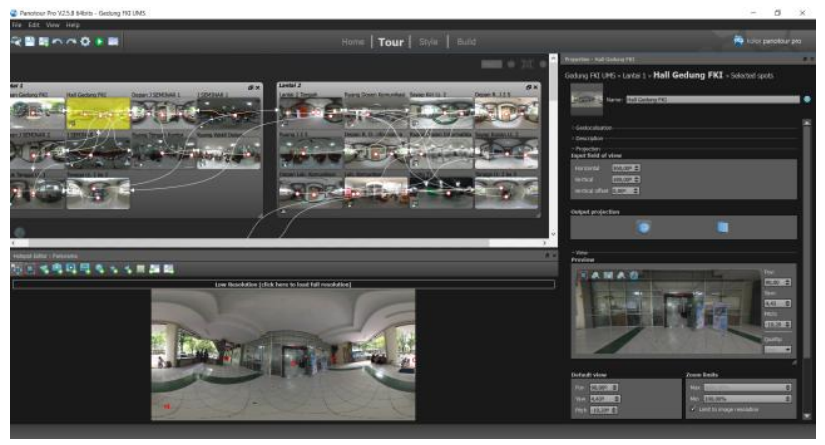

Gambar 5. Pembuatan Aplikasi VR 360 derajat di Kolor Panotour Giga

\section{B.Testing dan Analisis}

Setelah pembuatan aplikasi selesai, yang harus dilakukan selanjutnya yaitu pengujian apakah 
aplikasi tersebut berjalan dengan baik atau tidak. Penulis menggunakan metode Black Box, Usability, dan Komparasi.

\section{Uji Black Box}

Pengujian Black Box ini bertujuan untuk menunjukan fokus pada fungsional dari aplikasi. Hasil dari pengujian Aplikasi Pengenalan Gedung FKI UMS Menggunakan Virtual Reality 360 Derajat berjalan dengan baik menggunakan Uji Black Box.

Fungsi tombol dan output sesuai dengan konsep perancangan aplikasi yang telah dibuat. Aplikasi ini berbasis Website baik dibuka dengan komputer maupun mobile phone, tetapi disarankan menggunakan komputer agar lebih nyaman dijalankan. Berikut tampilan awal Aplikasi Pengenalan Gedung FKI UMS VR 360 derajat pada komputer (dapat dilihat pada Gambar 6).

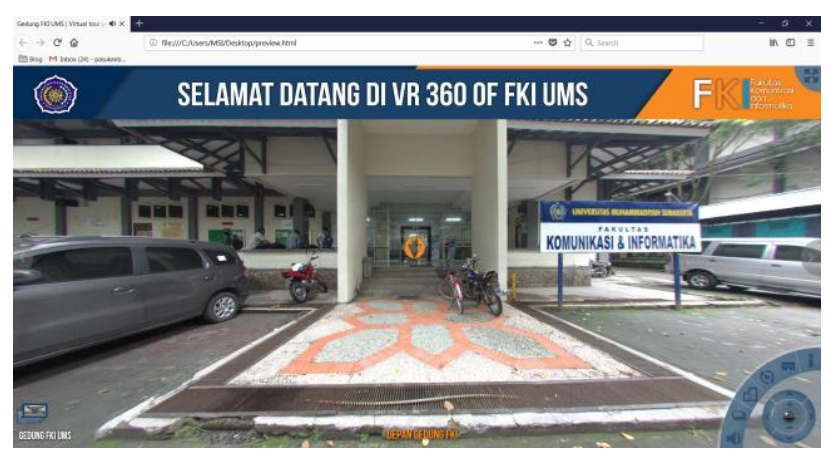

Gambar 6. Tampilan Awal Aplikasi Pengenalan Gedung FKI UMS VR 360 derajat pada komputer secara offline.

Hasil pengujian Black Box menunjukkan bahwa aplikasi 360 derajat ini berjalan dengan baik dalam web dikomputer dan mobile phone akan dijelaskan pada Tabel 6.

Tabel 6. Uji Black Box Aplikasi

\begin{tabular}{clll}
\hline No. & $\begin{array}{l}\text { Yang } \\
\text { diuji }\end{array}$ & Pengujian & Keterangan \\
\hline 1. & Menu & Tombol Next Scene \& & Lancar \\
& Utama & $\begin{array}{l}\text { Previous Scene } \\
\text { Drag Mouse/Touch }\end{array}$ & Lancar \\
& & \\
& & Screen & \\
& & Muncul keterangan \\
& nama tempat & Lancar
\end{tabular}

$\begin{array}{ll}\begin{array}{l}\text { Tombol anak panah } \\ \text { kebawah }\end{array} & \text { Lancar } \\ \begin{array}{l}\text { Backsound \& } \\ \text { dubbing aktif }\end{array} & \text { Lancar } \\ \text { Autorotation aktif } & \\ \text { Tombol Info } & \text { Lancar } \\ \text { Tombol VR Mode } & \text { Lancar } \\ \text { Tombol Autorotation } & \text { Lancar } \\ \text { Tombol Floor Plan } & \text { Lancar } \\ \text { Tombol Thumbnail } & \text { Lancar } \\ \text { Tombol Sound } & \text { Lancar } \\ \text { Tombol Fullscreen } & \text { Lancar } \\ \text { Tombol Move up, } & \text { Lancar } \\ \text { left, down, right } & \text { Lancar } \\ \text { Tombol Zoom in \& } & \\ \text { out } & \text { Lancar } \\ & \end{array}$

\section{Usability}

Pengujian ini memberikan kuesioner kepada responden sekaligus mencoba aplikasi VR 360 derajat secara online. Responden diminta untuk membuka aplikasi tersebut lalu mengisi kuesioner yang terdapat 9 pernyataan. Pengujian ini melibatkan mahasiswa/mahasiswi FKI UMS yang berjumlah 30 orang.

Hasil kuesioner dihitung dengan menggunakan rumus seperti pada Persamaan 1.

$$
\text { Persentase }=\frac{\sum \text { skor } \times 100 \%}{\text { Smax }}
$$

Pada kuesioner ini berjumlah 30 responden, sehingga

Skor Tertinggi $(\operatorname{Smax})=5 \times 30=150$

Tabel 7. Hasil pengisian kuesioner

\begin{tabular}{|c|c|c|c|c|c|c|c|c|}
\hline \multirow[b]{2}{*}{$\begin{array}{l}\mathbf{N} \\
\mathbf{0}\end{array}$} & \multirow[b]{2}{*}{$\begin{array}{l}\text { Ko } \\
\text { de }\end{array}$} & \multicolumn{5}{|c|}{ Jumlah Jawaban } & \multirow[b]{2}{*}{$\begin{array}{c}\text { Juml } \\
\text { ah } \\
\text { Skor }\end{array}$} & \multirow[b]{2}{*}{$\begin{array}{c}\text { Persen } \\
\text { tase }\end{array}$} \\
\hline & & $\begin{array}{l}\mathbf{S} \\
\mathbf{S} \\
( \\
5 \\
)\end{array}$ & $\begin{array}{l}S \\
( \\
4 \\
)\end{array}$ & $\begin{array}{l}\mathbf{N} \\
( \\
\mathbf{3} \\
)\end{array}$ & $\begin{array}{l}\mathbf{T} \\
\mathbf{S} \\
( \\
\mathbf{2} \\
)\end{array}$ & $\begin{array}{c}\mathbf{S} \\
\mathbf{T} \\
\mathbf{S} \\
(\mathbf{1})\end{array}$ & & \\
\hline 1 & $\mathrm{P} 1$ & $\begin{array}{l}1 \\
1\end{array}$ & $\begin{array}{l}1 \\
9\end{array}$ & 0 & 0 & 0 & 131 & $\begin{array}{c}87,33 \\
\%\end{array}$ \\
\hline 2 & $\mathrm{P} 2$ & 9 & $\begin{array}{l}2 \\
1\end{array}$ & 0 & 0 & 0 & 129 & $\begin{array}{c}86,00 \\
\%\end{array}$ \\
\hline 3 & P3 & 6 & $\begin{array}{l}2 \\
0\end{array}$ & 4 & 0 & 0 & 122 & $\begin{array}{c}81,33 \\
\%\end{array}$ \\
\hline 4 & $\mathrm{P} 4$ & $\begin{array}{l}1 \\
6\end{array}$ & $\begin{array}{l}1 \\
3\end{array}$ & 1 & 0 & 0 & 135 & $\begin{array}{c}90,00 \\
\%\end{array}$ \\
\hline 5 & P5 & $\begin{array}{l}1 \\
5 \\
\end{array}$ & $\begin{array}{l}1 \\
2\end{array}$ & 3 & 0 & 0 & 132 & $\begin{array}{c}88,00 \\
\%\end{array}$ \\
\hline 6 & P6 & $\begin{array}{l}1 \\
0 \\
\end{array}$ & $\begin{array}{l}1 \\
8\end{array}$ & 2 & 0 & 0 & 128 & $\begin{array}{c}85,33 \\
\%\end{array}$ \\
\hline 7 & P7 & 6 & $\begin{array}{l}1 \\
8\end{array}$ & 6 & 0 & 0 & 120 & $\begin{array}{c}80,00 \\
\%\end{array}$ \\
\hline
\end{tabular}




\begin{tabular}{|c|c|c|c|c|c|c|c|c|}
\hline 8 & P8 & $\begin{array}{l}1 \\
6\end{array}$ & $\begin{array}{l}1 \\
3\end{array}$ & 1 & 0 & 0 & 135 & $\begin{array}{c}90,00 \\
\%\end{array}$ \\
\hline 9 & P9 & $\begin{array}{l}2 \\
2\end{array}$ & 7 & 1 & 0 & 0 & 141 & $\begin{array}{c}94,00 \\
\%\end{array}$ \\
\hline \multicolumn{8}{|c|}{ Persentase Rata-rata } & $\begin{array}{c}86,89 \\
\%\end{array}$ \\
\hline
\end{tabular}

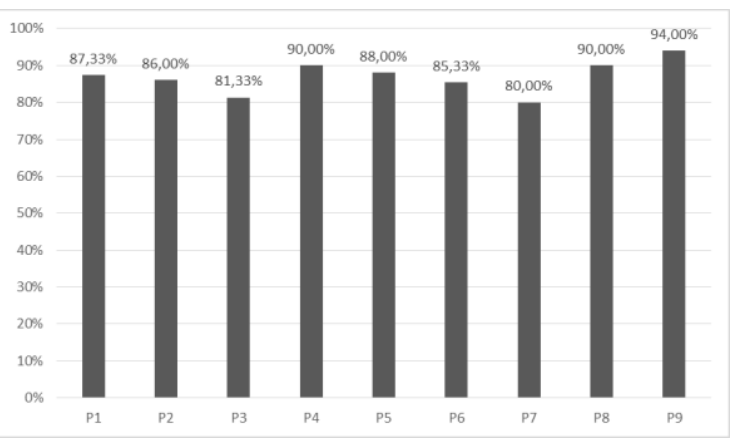

Gambar 7. Grafik hasil persentase masingmasing kode pernyataan

Keterangan:

P1 : Aplikasi mudah dioperasikan

P2 : Penggunaan menu atau fitur aplikasi mudah digunakan

P3 : Kelengkapan konten aplikasi

P4 : Informasi (teks maupun audio) yang disediakan mudah dimengerti

P5 : Tampilan aplikasi ini menarik

P6 : Aplikasi ini nyaman digunakan

P7 : Proses perpindahan dari menu ke menu lain berlangsung dengan cepat

P8 : Aplikasi ini bermanfaat bagi

pengguna

P9 : Aplikasi ini dapat membantu pengguna mengenal lebih dalam tentang FKI UMS

SS : Sangat Setuju

S : Setuju

$\mathrm{N} \quad$ : Netral

TS : Tidak Setuju

STS : Sangat Tidak Setuju

Berdasarkan Tabel 7 dan Gambar 7 di atas dapat disimpulkan bahwa hasil pengujian pada mahasiswa/mahasiswi FKI UMS menunjukan bahwa responden sebanyak $86,89 \%$, pengguna Aplikasi Pengenalan Fakultas Komunikasi dan Informatika Universitas Muhammadiyah Surakarta menggunakan Virtual Reality 360
Derajat dapat bermanfaat dan membantu mengenal lebih dalam tentang FKI UMS.

\section{Komparasi}

Penulis menganalisis TA yang terdahulu dengan TA penulis saat ini. Terdapat perbedaan dari masing-masing yang akan dijelaskan pada Tabel 8.

Tabel 8. Komparasi aplikasi

\begin{tabular}{|c|c|c|}
\hline Keterangan & Aplikasi 1 & Aplikasi 2 \\
\hline Judul & $\begin{array}{l}\text { Aplikasi } \\
\text { Pengenalan } \\
\text { Fakultas } \\
\text { Komunikasi dan } \\
\text { Informatika UMS } \\
\text { menggunakan } \\
\text { Virtual Reality } \\
\text { 360 Derajat }\end{array}$ & $\begin{array}{l}\text { Pemodelan Virtual } \\
\text { Reality One Day } \\
\text { Service sebagai Media } \\
\text { Informasi Pendaftaran } \\
\text { Mahasiswa Baru UMS }\end{array}$ \\
\hline $\begin{array}{l}\text { Jenis VR } \\
\text { Jumlah } \\
\text { Tempat }\end{array}$ & $\begin{array}{l}\text { Foto Panorama } \\
51 \text { Tempat/Titik }\end{array}$ & $\begin{array}{l}\text { Modeling Animasi 3D } \\
1 \text { Tempat/Titik }\end{array}$ \\
\hline Output & $\begin{array}{l}\text { Foto } 360 \text { Derajat, } \\
\text { Teks, Audio }\end{array}$ & Animasi, Teks, Audio \\
\hline Fitur & $\begin{array}{l}\text { Floor Plan (Denah } \\
\text { setiap lantai), Auto } \\
\text { Rotation, VR } \\
\text { Mode, Thumbnail } \\
\text { Foto, Informasi } \\
\text { teks dan suara }\end{array}$ & $\begin{array}{l}\text { Peta Ruangan, } \\
\text { Informasi teks dan } \\
\text { suara }\end{array}$ \\
\hline $\begin{array}{l}\text { Jenis } \\
\text { Aplikasi }\end{array}$ & $\begin{array}{l}\text { Berbasis Web } \\
\text { (Online atau } \\
\text { Offline) }\end{array}$ & $\begin{array}{l}\text { Berbasis Desktop } \\
\text { (Offline) }\end{array}$ \\
\hline
\end{tabular}

Berdasarkan dari kedua aplikasi di atas dapat disimpulkan bahwa aplikasi 1 memiliki fitur yang lebih banyak, selain itu implementasi aplikasi dapat dijalankan secara online maupun offline. Kemudian untuk spot tempat juga lebih banyak dibandingkan aplikasi 2. Sedangkan kelebihan aplikasi 2 yaitu lebih menarik dengan adanya animasi 3D. Untuk persamaannya yaitu sama-sama menampilkan tempat yang berisikan informasi baik teks maupun suara.

\section{Distribution}

Tahap distribution merupakan tahap terakhir dari 6 tahap yang sudah dipaparkan, pada tahap ini aplikasi diubah menjadi format HTML5 agar nanti dapat di publikasikan ke website secara online. Ukuran file aplikasi tersebut 
cukup besar mencapai 1,62 GB, jadi, proses penguploadan ke hosting memerlukan waktu yang lama. Aplikasi VR 360 Derajat FKI UMS ini akan diberikan kepada pihak fakultas, diharapkan dapat diunggah di situs resmi dari FKI UMS. Dengan demikian, aplikasi dapat digunakan oleh siapapun termasuk mahasiswa, calon mahasiswa baru, dan masyarakat umum.

\section{PENUTUP}

Berdasarkan pengujian dengan menggunakan Black Box, dapat disimpulkan bahwa aplikasi ini dapat berjalan dengan baik dan lancar pada website. Untuk membuka aplikasi lebih baik menggunakan komputer yang memiliki resolusi besar dibandingkan mobile phone. Aplikasi ini dapat dijalankan secara offline maupun online. Dengan begitu, tidak ada halangan bagi yang tidak memiliki jaringan internet. Tetapi lebih baik dijalankan secara online karena tidak semua orang memiliki aplikasi VR 360 tersebut.

Hasil pengujian menunjukkan bahwa sebanyak $90 \%$ responden, aplikasi ini menyajikan informasi (teks maupun audio) yang disediakan mudah dimengerti dan sebanyak $88 \%$ responden menyetujui bahwa aplikasi ini memiliki tampilan yang menarik. Kemudian responden sebanyak $87,33 \%$ menyatakan bahwa aplikasi ini mudah dioperasikan dan $86 \%$ responden juga menyatakan bahwa penggunaan menu atau fitur aplikasi mudah digunakan. Lalu, responden sebanyak 90\% menyetujui bahwa aplikasi ini bermanfaat dan $94 \%$ responden juga menyetujui bahwa aplikasi ini dapat membantu mengenal lebih dalam tentang FKI UMS.

Berdasarkan hasil aplikasi keseluruhan tersebut pasti memiliki kekurangan, dan beberapa saran yang membangun akan meminimalisir kekurangan tersebut agar kedepannya dapat lebih baik lagi. Saran yang pertama yaitu pengambilan foto sebaiknya menggunakan alat khusus agar mempermudah penggabungan foto atau meminimalisir foto yang tidak pas, yang kedua yaitu menambahkan pengambilan spot foto, ketiga yaitu mengurangi ukuran foto agar support dengan koneksi lambat, dan yang keempat yaitu kapasitas penyimpanan hosting ditingkatkan agar kinerjanya maksimal.

\section{DAFTAR PUSTAKA}

[1] Daud, Fahri R., Tulenan, V., Najoan, \& Xaverius B. N. (2016). Virtual Tour Panorama 360 Derajat Kampus Universitas Sam Ratulangi Manado. Teknik Informatika, Universitas Sam Ratulangi Manado, Vol 8, No. 1, hlm. 17.

[2] Pudyanto, Aditya Fatkur. (2014). Pemodelan Virtual Reality One Day Service sebagai Media Informasi Pendaftaran Mahasiswa Baru Universitas Muhammadiyah Surakarta. eprint.ums.ac.id (diakses pada tanggal 08 Maret 2018, pukul 14:06).

[3] Maulana, Much. R., Rusli, C. Y., \& Kurniawan, I. (2016). Pemanfaatan Virtual Reality untuk Pengembangan Kios Informasi Objek Wisata D Kota Pekalongan Berbasis Mobile. Jurnal LITBANG Kota Pekalongan, Vol 11, hlm. 23-41.

[4] Hardianti, L., Agus, F., \& Suyatno, A. (2014). Pengembangan Website Wisata Kota Samarinda Menggunakan Teknologi Foto VR 360. Program Studi Ilmu Komputer, FMIPA, Universitas Mulawarman, Vol 9, No. 3, hlm. 38-42.

[5] Zhu, Z., Xu, G., Riseman, E. M., \& Hanson, A. R. (2005). Fast Construction of Dynamic and Multi-Resolution $360^{\circ}$ Panoramas from Video Sequences. Image \& Vision Computing Journal, hlm. 1-33. 